\title{
MANAGING COMPLEXITY IN INDUSTRIAL COLLABORATIONS WITHIN TOOL \& DIE INDUSTRY
}

\author{
Günther Schuh, Alexander Sauer, Sebastian Döring \\ Laboratory for Machine Tools and Production Engineering (WZL) \\ RWTH Aachen University, Germany \\ G.Schuh@wzl.rwth-aachen.de \\ A.Sauer@wzl.rwth-aachen.de \\ s.Doering@wzl.rwth-aachen.de
}

\begin{abstract}
Joining collaborations and maintaining relationships within these has become a major concern for managers in industrial companies. This change to a large extent arises due to the globalisation of markets and the ongoing specialisation of companies, fostered by the possibilities of information technology and datacommunication. However, such a structural change requires adaptations by companies to fit the characteristics of industrial networks. In particular, the increasing complexity of collaborations in highly dynamic environments oftentimes is underestimated. This paper shows an approach to cope with this increasing complexity by the application of principles of complex systems from various sciences to collaborative enterprise networks regarded as sociotechnical systems, considering the tool and die industry as example.
\end{abstract}

\section{INTRODUCTION}

Today, industrial companies are challenged by a highly dynamic environment, which requires to develop and manufacture products at a high level of flexibility and quality for low costs. Companies are forced to specialise in order to minimise product complexity and reduce production costs (Schuh, 2006). As the complexity of a single task decreases the more partners are working on it, participating in collaborations and maintaining relationships within these has become a major concern for managers in industrial companies. Although collaborations are assisted by modern information technology and data-communication, both the complexity of coordination and, as a result, the resources needed for the control load of coordination, increase. It is proceeded on the assumption that there is an optimal point of lowest total complexity with a corresponding number and organisation of the partners, depending on the type of problem to be solved collaboratively.

However, studies reveal that the optimal collaborative system setup is difficult to find: currently, the failure rate of collaborative projects in manufacturing industry is near $50 \%$. Although there are multiple reasons for this, the underestimation of the system's complexity might chiefly be responsible for this. Regarding complexity, 
managers often ignore to match the type of the networks system setup with the type of task to be solved. In the case that they do take a matching into consideration, there is a lack of knowledge about network complexity that may lead to insufficient results. Reliable models and instruments for managers to handle both the internal complexity of networks and the complexity of the environment are not available, yet. Moreover, there exist multiple unforeseen, emergent network effects in elasticity and controllability as well as in overall network and production system behaviour, which increase the system's complexity. A practical example for the mentioned developments and problems is given by the present situation of the tool and die industry.

\section{THE TOOL AND DIE INDUSTR}

\subsection{Today's Situation}

Tool and die making has become an important but critical function within a demanding field of tension (Eversheim, 2002). Established between product development on the one hand and manufacturing and assembly on the other hand, tool and die making contributes both sides up- and downstream the value chain. Concerning the product development, it provides know-how for the specification of parts and the development of efficient production processes. For manufacturing and assembly, the tool and die making process provides productivity and operational availability. Therefore, the tool and die making process is a key process for realising shortened time-to-market goals and competitive cost structures (see Figure 1).

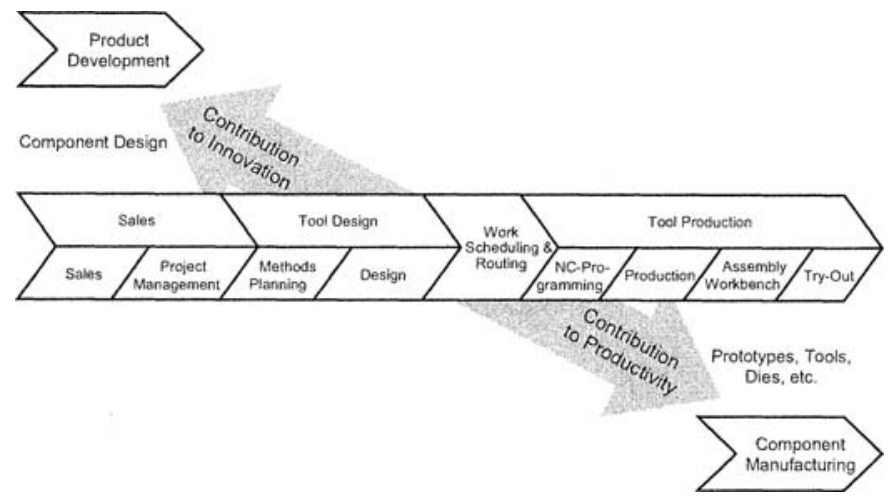

Figure 1 - Contributions of a tool and die shop to adjacent value chain processes

Due to its key position within the value chain, the tool and die shops make various contributions to the value and economic success. The first type of earnings is made by tool construction and manufacturing. In addition, productivity is provided by maintenance and repair of tools and dies. Thus, from individual repair and maintenance orders of flat-rates, the second type of earnings can be made. While maintenance usually requires a medium- or long-term planning and consequently is 
considered to be quite foreseeable, repairs mostly fall due unexpectedly. To decrease wear and improve stability, tools and dies could be produced at a higher level of quality. This would minimise the likeliness of a breakdown on the one hand, but, at the same time, increase the expenses for manufacturing, decrease the flexibility and extend the time-to-market on the other hand. As a consequence of the higher manufacturing expenses, the competitive pressure that is mainly caused by new entrants from Eastern European Countries and the Far East, increases. If a tool and die shop decides to produce at a lower level of quality, more spare capacity has to be kept in the shop in order to guarantee productivity by quickly reacting to tool or die breakdowns. This inevitably leads to underutilisation and, as a result, to additional personnel costs. However, companies have to spend an availability premium caused by unexpected production breakdowns or underutilisation of their production means in the tool shop (Fricker, 2005). Collaboration seems to be a strategic option to minimise additional costs and availability premiums.

\subsection{Collaborations As Strategic Option}

A promising approach for tool and die shops to cope with the mentioned trade-offs is to collaborate in regional networks. Sharing capacities enables the collaborating companies to highly reduce their spare capacity and consequently decrease the rate of underutilisation. By joining individual competencies an optimal tool supply can be achieved at a higher level of quality. Moreover, the Intellectual Capital of all participating partners in industrial collaborations can be significantly increased by application of the optimal partners and a balance of power within the collaboration (Sauer, 2005). In addition, the flexibility to react to changing customer needs can be increased and the time-to-market can be shortened.

There exist various approaches and models supporting such collaborations oftentimes called virtual organizations (e.g. Sydow, 1992; Schuh, 1998; Goranson, 1999). However, collaborations with other tool and die makers - even with competitors - require adaptations by companies in order to fit the characteristics of industrial networks. Although the conditions for collaborations have been improved during the last years - especially in terms of information technology and datacommunication - the management of tool and die shops needs to tackle the increasing complexity of networked structures (Colotla, 2003). This can be pointed out with an example:

The Plastics-Cluster Upper Austria is an industrial network initiated by the Austrian State with approximately 300 partners from the industrial sectors tool and die making, plastics machine engineering and plastics processing. Most of the participating enterprises are small and medium sized and operate as suppliers for the automotive industry. The network targets the pooling of competencies to improve the innovation capacity and to strengthen the competitive position of the participants. The network is provided by a systematic cluster management for a continuous change process support in the fields of information and communication, qualification, collaborations and projects as well as marketing and public relations. Even though the cluster is well-developed in its normative and strategic alignment, there is a lack in the development of tactical and operative management. In particular, the project planning and realisation is allocated to the project partners 
without any systematic support by the management. However, this support is essential to cope with the complexity emerging from collaborative order processing.

\section{MANAGING COMPLEXITY}

Reducing and managing complexity mostly aims at structuring organisations and implementing organisational changes. An example for such an approach can be found in modular product configurations (e.g. Dekkers and Sopers, 2001; Schuh et al., 1998; Schuh, 2005) or Release Engineering (Schuh, 2004). Regardless of how companies build on existing capabilities that are present in available resources and current structures, alternatives for coping with external changes remain limited. Adapting tool and die shops and their networks to the dynamics of the environment requires more than one-time interventions that are seeking for stability. Companies have to increase their complexity handling capability, which means the ability to cope with the changes in their environment and the associated complexity pouring in (Boswijk, 1992). Further on, they have to build on existing capabilities for new situations or incorporate new knowledge in order to create new capabilities for a better survival in the global competition. However, the applied strategy must be chosen carefully; the world of management has been overfed with theories that might have been adequate to at least some enterprises dealing with contemporary challenges of industry, but not to others (Micklethwait, 1996) - for example Business Process Reengineering or Core Competencies. All these theories have in common that their foundations stem from a variety of presuppositions pertaining to different factors that might directly influence the rate of success of an organisation at one place and time. Direct transferences of these approaches to networked enterprises regularly fail as they lack problem-oriented interdisciplinary inferences. A new perspective to advance research in industrial collaborations can be achieved by incorporating findings from different fields of sciences dealing with complex systems.

\subsection{Collaborations As Socio-Technical Systems}

Several approaches of General Systems Theory exist that aim at a specification of generic organisational concepts. However, none of these systems theories have been adequately implemented in the domain of networks, yet. Most methodologies apply systems theories in order to model organisations from a cybernetic point of view and combine these theories with a socio-technical approach for the design of new organisational structures. The systems theories might require some further elaboration by means of the adoption of theories for complex systems, networks and biological models. Concerning this level, the validity of the design approach should be scrutinised. The design approach has the characteristics of static, one-time interventions, which industrial companies have to avoid due to their severe effects on organisations. The review of other theories, such as complex systems theories, networks theories and biological models, can facilitate the identification of the companies' structures and their arrangement in networks, which is required for adapting to environmental changes and continuous change. 
Human-influenced complex networks have common properties, which are hardly in line with existing cybernetic approaches. The lack of network-orientation within such systems theories becomes obvious, considering the fact that most companies nowadays act in such networks - here one must draw the conclusion that existing approaches remain hypothetically and are not capable of representing the reality of networking companies. According to Milgram, the so-called small-world property states that the average path length in the network is relatively small compared to the system size (Milgram, 1967). In particular, this is true for the scattered tool and die branch that is characterised by individual human relations between regional enterprises in order to hedge capacities.

Another property of complex networks is clustering, i.e. the increased probability of node pairs being connected with neighbour nodes that are also connected. Therefore, increased efforts were made to identify other measures of complex (enterprise) networks (Fricker, 1996). The clustering tendency particularly can be found in the tool and die industry. There are for example three established clusters in Europe, located in Italy, Portugal and Germany, and one upcoming cluster in Czechia. Beyond these clusters, most tool and die shops belong to companies of the production industry that they mainly support internally. There exist only a few independent tool and die shops scattered outside the clusters.

The most important property is the distribution of degrees, i.e. the distribution of the number of links between the nodes. It has been pointed out that several real world networks have scale-free distributions, often in the form of a power law. In these networks, a huge number of nodes have only one or two neighbours, whereas a couple of them are multiple-connected. The three specific properties of complex networks mentioned hardly appear in the original systems theories such as the Applied Systems Theory.

While a number of models have been proposed to generate networks with different combinations of the three properties, each of these models describes a process that ends up in a network having the desired properties. Less effort has been devoted to the design of a dynamic system that would not only generate but maintain such a network. While there exist only few model approaches (Friedli, 2000; Schwaninger, 2000), most of them are based on the assumption that the system size or the number of links increases. However, in some industries, such as the tool and die industry, the system size and number of links also decrease as a consequence of a consolidation of the sector. Therefore, advances in network theories should focus on the dynamics of socio-technical systems accounting for the typical properties of complex networks.

\subsection{Collaborations As Complex Systems}

In the early 1980's, the paradigm of self-organisation emerged and opened a new branch for the description and control of complexity (Jost, 2004). With the increasing number of elements in artificial systems their control became increasingly complex (Bar-Yam et al., 2003). As a result, the deterministic top down approach to systems control became inefficient, or even impossible, in particular for highly dynamic environments. However, it is assumed that in the field of complexity simple and comprehensible laws exist. The field of study for complex systems holds the assumption that the dynamics of complex systems is founded on universal 
principles that may be used to describe disparate problems ranging from particle physics to the economics of societies (Kauffman, 1993). The development of complexity science means a shift in scientific approach having the potential to profoundly affect business, organisations and government. The objective is to comprehend complex systems whilst considering the questions: Which principles govern their behaviour? How do they adapt to change? How can they learn efficiently? How can they optimise their own behaviour?

The term complexity can represent two meanings that are relevant to this research:

- As an expression of structure, mostly internally oriented; either being part of networks or of an individual system;

- As an expression of emergence, associated with new behaviour and complexity emerging from environment.

To cope with emergence, different entities might develop different types of complexity handling capability; under these conditions, balance will hardly be achieved. Within the scope of this research only paradigms that address the dynamics of industrial networks and the environment will be chosen for an elaboration.

Agent-Based Modelling is a new and special branch of computer simulation that emerged as a methodology for studying complex systems (Buchanan, 2004). AgentBased Models consist of agents, which have states and behavioural rules as well as an environment. In the environment, which is either spatial (e.g. a rectangular grid) or non-spatial (e.g. an abstract trading community), interactions among agents take place. The interactions can either be direct where the action immediately changes the state of the partner, or indirect when the action changes the environment which, in turn, causes the partner's state to change. Traditional social sciences, especially classical economics, have very strong assumptions concerning the rationality of agents. Most Agent-Based Modelling use bounded rational agents that have only local, limited information, and limited ability and time to process that information. This is comparable to the real-life situation in the tool and die industry: small enterprises with highly restricted ressources and rationality that do not know much about the world market.

Both complexity sciences and network sciences are two sides of the same coin for future research in different disciplines. Only if a profound and interdisciplinary understanding of complex adaptive systems is gained, quantum leap improvements in handling and purposefully using these systems will be attained. In a close interaction of both approaches the fields can mutually benefit from each other's experience, knowledge and approved solutions. Thus, the potential progress in both disciplines, complexity science and network sciences, may not only be additive but multiplicative. Regarding the tool and die industry that means to focus on the essential aspects including network, collaboration and relationship management.

\subsection{Evolutionary Approaches}

The progress in the science of complexity has also affected models in evolutionary biology. Especially, the models of developmental pathways and co-evolution deserve closer attention with respect to industrial networks. Environmental changes (concerning market domains and technology) can be considered by means of 
evolutionary biological models. The most accredited models that describe the interaction between organism and environment are:

- The NK-model based on Fitness Landscapes (Kaufmann, 1993);

- The Evolutionary Stable Strategies, application of game theories to the domain of biology (Meszéna, 2001).

A preliminary study of evolutionary mechanisms and their meaning for organisational development reveals the importance of the criteria of sustained fitness, optimisation and mutation in order to reach a local optimum and evolvability. This means the capability to penetrate the new product-market combinations and disperse in combination with bifurcation processes (Dekkers, 2004). Regarding several current scientific elaborations on strategic management, the importance of the fitness concept becomes obvious (Fricker, 2005; Frick, 2005; Sauer, 2005). Fitness not only levers synergy potentials as shown in production industry, but also increases intellectual capital within collaborative processes. However, the strategic position and the business model have to support the offered products and services as backbone.

Several approaches exist in literature to describe the evolution of collaboration. During the past decade, advances have been made in game theories, the descriptions of co-evolution, altruism, etc. within the domain of evolutionary biology. These advances can be transferred to the domain of organisations and networks (Dekkers, 2004), yielding more appropriate models to describe collaborations; in turn this might lead to a higher effectiveness of collaborations and a more purposeful development of cooperation. Additionally, a more effective collaboration will result in adaptations by agents in networks to the dynamic environment.

\section{CONCLUSION}

What kind of correlation exists between type and complexity of the collaborative problem and the most suitable underlying network structure for solving it?

With the field of complexity research still being a patchwork of scattered insights, a pragmatic and interdisciplinary approach holds the potential of yielding valuable insights into complexity modeling in today's networked production industry. The most common approaches focus on the complexity of structures having a static character; this links to the most common system theories. In our opinion, the dynamic dimension of complexity, found in recent progress of various sciences, will fit the characteristics of industrial networks. The scientific objective should be to provide a properly designed framework-of-thought for the implementation of complexity management infrastructures, which rely either on state-of-the-art information technologies or on new insights into architecture and characteristics of complex systems.

The implementation of this framework enables companies to react more flexible when market opportunities arise, thus increasing their competitive position, and to manage the networks they participate in more adequately. The adaptation to changing environmental conditions and the drive for innovation and fast product development will benefit from the research results. New paradigms for industrial networks will stretch beyond the traditional issues of trust, power, and supply chain management. Although the development of tools will be the next but one step, the 
results should guide companies' management of network dynamics, their higher degree of specialisation, the development and implementation of technologies, and their development of appropriate long or short term relationships. This will reflect on both the optimisation of the supply chains and the speed of innovation and product development. As shown for the tool and die industry, there is a strong demand for such new guidelines to meet growing world-wide chances, risks and challenges. Particularly, industry sectors such as the tool and die industry with small, broadly scattered and highly specialised companies, can benefit from new guidelines for the management of complex industrial networks.

\section{REFERENCES}

1. Bar-Yam, Yaneer; Tucker Brian; Furness, Colin; Olsen, Jesse; McGuirl, John; Oztas, Nail; Milhiser, Will. Complex Social Systems: Rising Complexity in Business Environments. Discussion paper, Cambridge: New England Complex Systems Institute, 2003.

2. Boswijk, Hendrikus Krijn. Complexiteit in evolutionair en organisatorisch perspectief; het zoekennaar balans tussen vermogens en uitdagingen. Rotterdam: Erasmus Universiteits Drukkerij, 1992.

3. Buchanan, Mark. It's the Economy, Stupid. New Scientist 2004; 182: 34-37.

4. Colotla, Jan.; Shi, Yong-Jiang; Mike J. Gregory. Operation and performance of international manufacturing networks. International Journal of Operations and Production Management 2003; 10: 11841206.

5. Dekkers, Rob; Sopers, F.P.M. "Logistic Control and the Order Entry Point." In: Hanus, D.; Talácko, J., ed. Prague: [CD-Rom] Proceedings $16^{\text {th }}$ International Conference on Production Research, 2001

6. Dekkers, Rob. Adapting Industrial Organisations to the Dynamics of the Environment. Rotterdam: 2004

7. Eversheim, Walter. et al. Was die Spreu vom Weizen trennt. Werkzeug- und Formenbau 2002; 1: 8-11.

8. Frick, Lutz. Erfolgreiche Geschäftsmodelle im Werkzeugbau. Dissertation: RWTH Aachen University, 2005.

9. Fricker, Achim. Eine Methodik zur Modellierung, Analyse und Gestaltung komplexer Produktionsstrukturen. Dissertation: RWTH Aachen, 1996.

10. Fricker, Ingo Christian. Strategische Stringenz im Werkzeug- und Formenbat. Dissertation: RWTH Aachen, 2005

11. Friedli, Thomas. Die Architektur von Kooperationen. Dissertation: University of St. Gallen, 2000.

12. Goranson, H.T. The Agile Virtual Enterprise. Westport: Quorum: 1999.

13. Jost, J. External and internal complexity of complex adaptive systems. Theory in Biosciences; 123: 34-37.

14. Kauffman, Stuart Alan. The Origin of Order. Oxford: Oxford University Press, 1993.

15. Meszéna, Geza.; Kisdi, Éva.; Dieckmann, Ulf; Geritz, Stefan A.H.; Metz, Johan A.J. Evolutionary Optimisation of Models and Matrix Games in the Unified Perspective of Adaptive Dynamics. Selection. 2001; 2: 193-210.

16. Micklethwait, John; Woolridge, Adrian. The witch doctors. London: Heinemann, 1996.

17. Milgram, Stanley. The Small World Problem. Psychology Today 1967; 2: 60-67.

18. Sauer, Alexander. Machtbasierte Entwicklung von Intellectual Capital in Kollaborationen der produzierenden Industrie. Dissertation: RWTH Aachen, 2005.

19. Schuh, Günther; Millarg, Kai, Göransson, Asa. Virtuelle Fabrik - Neue Marktchancen durch dynamische Netzwerke. München: Hanser, 1999.

20. Schuh, Günther. Release Engineering - An Approach to Control Rising System-Complexity. Annals of CIRP 43/1, 2004, 167-171.

21. Schuh, Günther. Produktkomplexität managen. München: Hanser, 2005.

22. Schuh, Günther. Changen Management - Prozesse strategiekonform gestalten. Berlin: Springer, 2006.

23. Schuh, Günther; Schwenk, Urs; Speth, C. Komplexitätsmanagement im St. Galler ManagementKonzept. lo Management 1998; 3: 78-85.

24. Schwaninger, Markus. Das Modell lebensfähiger Systeme. Discussion Article No. 35, Universität St. Gallen, 2000.

25. Sydow, Jörg. Strategische Netzwerke - Evolution und Organisation. Wiesbaden: Gabler, 1992. 